\title{
An Apparatus for the Analysis of Micro-Amounts of Gases in Iron and Steel by Vacuum Fusion-Mass Spectrometry*
}

\author{
By Naoharu Yamaguchi**, Hideo Kanno** \\ and Ôhiko Kammori**
}

\begin{abstract}
A mass spectrometer was applied for vacuum fusion analysis of micro-amounts of gases in iron and steel produced by vacuum melting and vacuum casting. The gases extracted from the metal specimen in a vacuum fusion furnace were collected directely in the gas reservoir through a mercury diffusion pump, and the individual constituents were determined by the mass spectrometer (Gas Detector, ATLAS-WERKE AG.). The limits of detection for this apparatus were $0.07 \mu \mathrm{g}$ of oxygen, $0.1 \mu \mathrm{g}$ of nitrogen and $0.035 \mu \mathrm{g}$ of hydrogen. The analysis tos's approximately 30 minutes. From the extraction curve with vacuum fusion, it was proved to be extracted gases from iron and steel within 2 minutes.
\end{abstract}

(Received March 17, 1969)

\section{Introduction}

With the recent advent of new techniques for vacuum melting and vacuum casting, it is now possible to obtain steels with extremely low contents of gases such as oxygen and nitrogen, and the effect of micro-amounts of gases on the physical and mechanical properties of steel is studying with interest. Therefore, the determination of these gases has been considered necessary.

Vacuum fusion-micro-orsat ${ }^{(1)(2)}$ and vacuum fusionmanometric methods ${ }^{(1) \sim(3)}$ are well known methods for the determination of these gases in metals, but these methods are of insufficient sensitivity and less reproducible in less than $10 \mathrm{ppm}$. It is not effective to increase the sample size because of the increased degassing time, the increased blank gases and the unfavorable work for routine.

In recent years, new techniques such as inert gas fusion-electric conductometry ${ }^{(4)}$ and -coulomatic method $^{(5)}$, emission spectrometry ${ }^{(6)}$, gas chromatography (7), the fast-neutron activation method ${ }^{(8)}$ and infrared spectrometry ${ }^{(9)}$ have been developed, but these methods for determining micro-amounts of gases are of insufficient sensitivity, too.

Since mass spectrometry is capable of analyzing small amounts of gases quantitatively with high sensitivity.

* This paper was originally published in Japanese in J. Japan Inst. Metals, 31 (1967), 679.

** Tokyo Research Institute, Yawata Iron \& Steel Co., Ltd., Kawasaki, Japan.

(1) Rapid Analysis of Iron and Steel, ed. by The 9 th Committee of Japan Society for the Promotion of Science, Maruzen, Tokyo, (1958), p. 480.

(2) I. Ogahara : Jikken Kagaku Koza, vol. 15, Analytical Chemistry (II), ed. by The Chemical Society of Japan, Maruzen, Tokyo, (1958), p. 350.

(3) Nakagawa : Tekko Kagaku Bunseki Zensho, vol. 8, ed. by The 9 th Committee of Japan Society for the Promotion of Science, Nikkan Kogyo, Tokyo, (1963), p. 33.

(4) M. Codell and G. Norwitz : Anal. Chem., 30 (1958), 524

(5) H.Goto, S.Ikeda and A. Ônuma : J.Iron and Steel Inst., 50 (1964), 2126.

(6) V.A. Fassel and R.W.Tabeling : Spectrochim. Acta, 8(1956), 201, etc.

(7) R. Lesser and H. Gruber : Z. Metallk., 51 (1960), 495, etc.

(8) R. F. Coleman : Analyst, 87 (1962), 590. and in short time, this technique has been used for the analysis of gases obtained by vacuum fusion ${ }^{(10) \sim(14)}$. Most works, however, carried out for oxygen of more than $10 \mathrm{ppm}$ and were not available for routine analysis. Aspinal (15) described the equipment capable of determining less than $10 \mathrm{ppm}$ of oxygen.

The preliminary test for vacuum fusion-mass spectrometry was carried out with a CEC 21-103C mass spectrometer at our institute, and this technique was found to be most suitable for the analysis of microamounts of gases in iron and steel.

The object of the present work is to develop an apparatus suitable for routine analysis of iron and steel with low gas contents. The apparatus was devised so that a small commercial mass spectrometer, a gas handling system and a conventional vacuum fusion system could be coupled in series. The mass spectrometer was improved to be able to determine oxygen, nitrogen and hydrogen simultaneously and rapidly, and the gas handling system has an inlet to introduce the standard gases for calibrating the sensitivities and pattern coefficients.

In this method, specimens of about $1 \mathrm{~g}$ are dropped into the graphite crucible which is heated to $1700^{\circ} \mathrm{C}$ by high frequency induction $(1 \mathrm{~kW}, 400 \mathrm{kc})$, and 5 minutes are allowed for gases given off to be collected in the gas reservoir, and the individual constituents are determined mass-spectrometrically. The general arrangement of the apparatus is shown in Fig. 1. It is compact ; $130 \mathrm{~cm}$ in width, $155 \mathrm{~cm}$ in height and $45 \mathrm{~cm}$ in depth excluding a high frequency generator.

\section{Gas extraction unit}

A vacuum fusion unit is similar to the usual one, but a cold trap or dryer to eliminate water vapor in the extracted gases, and a McLeod gauge to measure total

(9) Th. Kraus and O. Winckler : Rev. Mét., 61 (1964), 87, etc.

(10) W. M. Hickam : Anal. Chem., 24 (1952), 362.

(11) E. Kato : Japan Analyst, 2 (1953), 98.

(12) M. Goto : Mass Spectroscopy (Japan), No.8, (1957), 30

(13) J. F. Martin, et al. : Trans. Met. Soc. AIME, 212(1958), 514.

(14) D. Hazelby : J. Sci. Instr., 42 (1965), 486.

(15) M. L. Aspinal : Analyst, 91 (1966), 33. 


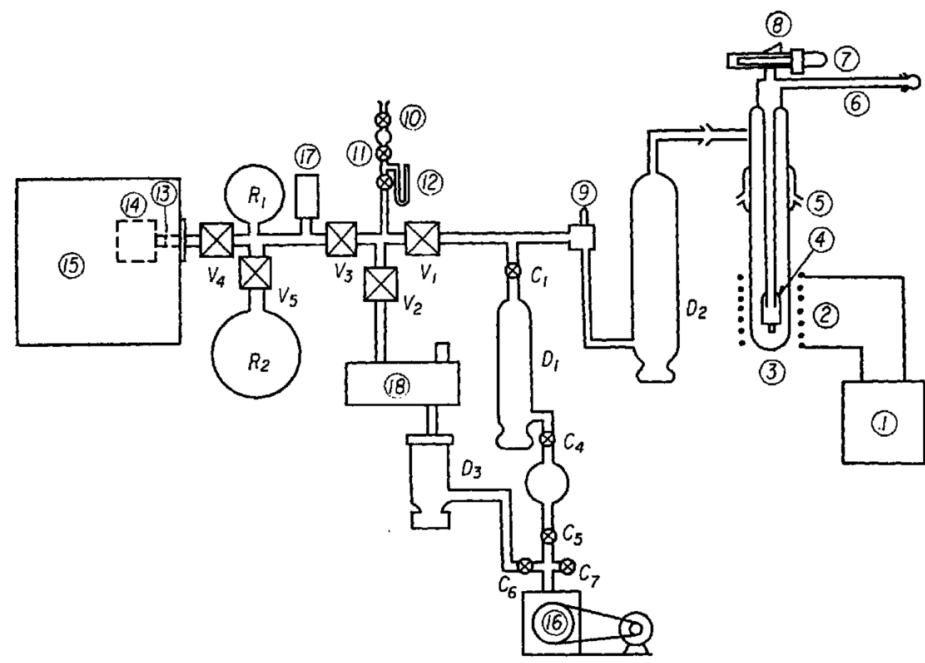

(1) High frequency Oscillator $(400 \mathrm{kc}, 1 \mathrm{~kW})$ (2) Induction coil (3) Quartz furnace tube $(40 \mathrm{~mm} \phi)$ (4) Clear quartz cup (5) Water jacket (6) Sample loading arm (7) Glass enclosed iron (8) Optical prism (9) Mercury cock (10) Connector for gaseous sample (11) Standard volume $(1.00 \mathrm{~mL}$ ) (12) Mercury manometer (13) Gold leak (14) Ion source (15) Mass spectrometer (16) Oil mechanical pump (17) Pirani gauge (18 Liquid nitrogen trap $R_{1}$ : Gas reservoir (2l) $\mathrm{R}_{2}$ : Gas reservoir $(3 l) \mathrm{D}_{1}$ : Mercury diffusion pump $\mathrm{D}_{2}$ : Mercury diffusion pump $D_{3}$ : Oil diffusion pump $C_{1} \sim G_{7}$ : Glass cocks $V_{1} \sim V_{5}:$ Metal valves

Fig.1 Schematic diagram of gas analyzer for iron and steel

amounts of gases are removed.

A slightly modified Guldner-Beach furnace $^{(16)}$ shown in Fig. 2 is used in the furnace section. The graphite crucible is placed in the quartz cup and insulated by graphite powder $(-200$ mesh $)$ and a felt made of graphite fibre ${ }^{(17)}$.

The quartz furnace tube is joined to the glass manifold by means of the ground taper cooled with water. The graphite crucible has a volume of $1.6 \mathrm{~mL}$ and is spacious enough to melt $12 \mathrm{~g}$ of iron and steel.

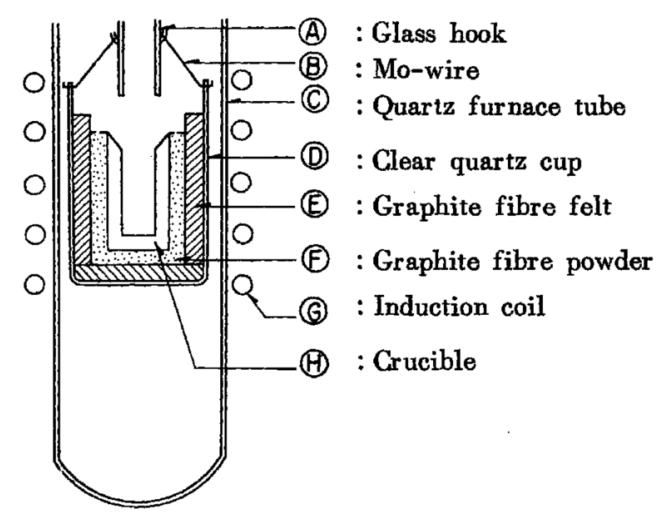

Fig.2 Furnace section

\section{Analytical section}

The mass spectrometer used is a gas detector manufactured by ATLAS-WERKE AG., and its specifications are shown in Table 1: This instrument which was originally manufactured as a leak detector

(16) W. G. Guldner and A. L. Beach : Anal. Chem., 22(1950), 366.

(17) Ô. Kammori, N. Yamaguchi and H. Kanno : J. Japan Inst. Metals, 31 (1967), 869. was improved in resolving power, with a scanning device to analyze the gaseous sample. Moreover, it was improved to be convenient in routine analysis by the present authors; the spectrum can be scanned from $M / e=4$ to 46 in 4 minutes electrically, and one more collector in addition to the usual collector (radius of ion trajectory : $28 \mathrm{~mm}$ ) was set at $14 \mathrm{~mm}$ as a radius of ion trajectory where ions of hydrogen is collected. Consequently, carbon monoxide, nitrogen and hydrogen are measured at the same strength of magnetic field. Two collectors are switched at the grid resistor in the preamplifier. A two-pen recorder and an attenuator (1:3:10:30:1:00: $300: 1000$ ) are attached to the detector.

The gas handling system is made of stainless steẹl and partly of glass and valves available commercially are used. Two gas reservoirs are set to adjust the pressure of the extracted gases to a suitable value and a rough estimate of pressure is made by Pirani gauge. When the amount of the extracted gases is less than $150 \mu \mathrm{L}$, the gas reservoir of $2 \mathrm{~L}$ is used, and when more than $150 \mu \mathrm{L}$, both reservoirs are used.

Table 1 Specifications of mass spectrometer (Gas detector of ATLAS-WERKE AG.)

\begin{tabular}{|c|c|}
\hline Resolving power $(M / \Delta M)$ & 35 \\
\hline Mass range $(M / e)$ & $\begin{array}{l}4 \sim 46 \text { or } 2 \sim 23 \text { (by exchange } \\
\text { of magnet) }[2,4 \sim 46]\end{array}$ \\
\hline Sensitivity & $1 \times 10^{-10}$ Torr. \\
\hline Radius of ion trajectory & $28 \mathrm{~mm}[14 \mathrm{~mm}$ for $M / e 2]$ \\
\hline Angle of ion deflection & $180^{\circ}$ \\
\hline Scan speed & $\begin{array}{l}{[4 \mathrm{~min} \text { to scan } M / e=4 \sim 46} \\
\text { (electric scanning)] }\end{array}$ \\
\hline Electron accelerating voltage & $120 \mathrm{~V}$ \\
\hline Ion accelerating voltage & $50 \sim 800 \mathrm{~V}$ \\
\hline Ion source temperature & not control \\
\hline Strength of magnetic field & $\begin{array}{l}2800 \text { or } 2000 \text { gauss (permanent } \\
\text { magnet) }[2800 \text { gauss }]\end{array}$ \\
\hline Measurable pressure (max.) & $1 \times 10^{-3}$ Torr. \\
\hline Vacuum system & $\begin{array}{l}\text { Oil mechanical pump, Oil dif- } \\
\text { fusion pump, Liquid nitrogen } \\
\text { trap, Bakable to } 150^{\circ} \mathrm{C}\end{array}$ \\
\hline Power requirement & $220 \mathrm{~V}, 50 / 60$ cycles, $750 \mathrm{VA}$ \\
\hline Size & $\begin{array}{l}485 \text { wide } \times 520 \text { high } \times 445 \text { deep } \\
(\mathrm{mm})\end{array}$ \\
\hline Weight & $70 \mathrm{~kg}$ \\
\hline
\end{tabular}

[ ] : After the modification by authors

For calibrations of the sensitivities and the pattern coefficients of carbon monoxide, nitrogen, hydrogen and other gaseous components such as methane, ethylene and carbon dioxide present in the extracted gases, standard gases are introduced through the connector for the gaseous sample and the introduced amount is known by measurement of the pressure in the standard volume $(1.00 \mathrm{~mL})$ with a mercury manometer.

The mass spectrometer and gas handling system are 
kept running overnight to hold a high vacuum and to work the electric circuit constantly.

\section{Method of Analysis}

\section{Analytical procedure}

For the analysis of steel, the specimen size is $6 \mathrm{~mm}$ in diameter and $6 \mathrm{~mm}$ in length. The preparation of the specimen's surface is usually abraded with a file or silicon carbide paper (400-grit), washed in benzene, and then dried with air. After weighing, the specimens are placed as quickly as possible in the sample loading arm.

After the crucible and specimens have been set in position, the initial evacuation is carried out by the rotary pump until the pressure falls below $10^{-2}$ Torr. The mercury diffusion pump is started and left until the pressure becomes $10^{-5} \sim 10^{-6}$ Torr.

With the high frequency generator, the graphite crucible is heated slowly to the outgassing temperature $2300^{\circ} \mathrm{C}$, maintained at that temperature for three hours, and lowered to the analytical temperature $1700^{\circ} \mathrm{C}$. After the gases evolved at the analytical temperature for 5 minutes become less than $10 \mu \mathrm{L}$, a blank sample (cast iron) is dropped into the graphite crucible. After evacuation is continued a little longer, the specimens to analyze are dropped. The blank value is determined for each analysis.

The time schedule of the analytical procedure is shown in Table 2, and the time required for analysis of a single specimen is 30 minutes excluding the preparation and the calculation.

Table 2 Schedule of analytical procedures

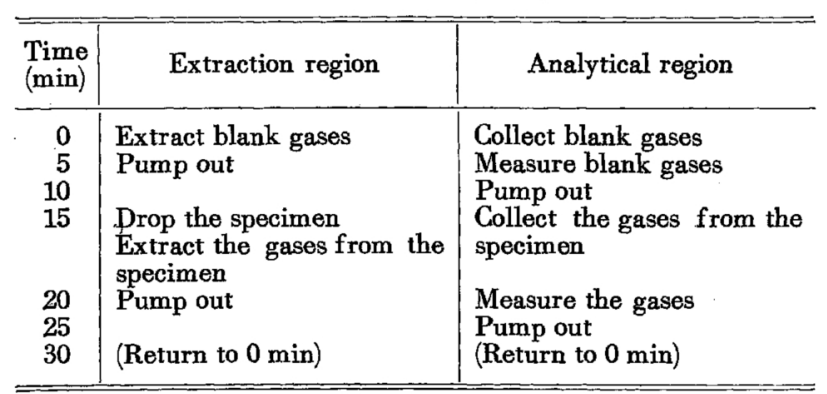

\section{Mass spectrum and calculation}

Both the sensitivity and the pattern coefficient of each component are obtained using standard gases. In this experiment, the sensitivities are indicated as the ratio of the height of a base peak to the amount of gas ; that is, about $100 \mu \mathrm{L}$ of the standard gas is introduced to the standard volume, and the pressure of it is measured accurately with a mercury manometer. After the gas is transferred to the gas reservoir, the spectrum is scanned, and the height of the base peak in the spectrum obtained is devided by the amount of gas. The pattern coefficients are obtained from the ratio of other peaks to the base peak.

The sensitivities and the pattern coefficients are shown in Table 3. The detectable limits are shown in the table, but for the micro-amounts of gases the sensitivities can be increased to $100 \sim 1000$ times that of the values in the same table by exchanging the grid resistor in the preamplifier or varying the magnification of the attenuator.

In the three major components, carbon monoxide, nitrogen and hydrogen in the extracted gases, hydrogen can easily be determined from the peak height of $M / e=2$, because the peak at $M / e=2$ is a unicom-

Table 3 Pattern coefficients and sensitivities of standard gases

\begin{tabular}{|c|c|c|c|c|c|}
\hline \multirow{6}{*}{ 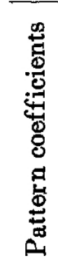 } & \multicolumn{2}{|c|}{$M / e$} & $\begin{array}{c}\text { Carbon } \\
\text { monoxide }\end{array}$ & Nitrogen & Hydrogen \\
\hline & \multicolumn{2}{|c|}{2} & 一 & - & 100 \\
\hline & \multicolumn{2}{|c|}{12} & 8.67 & - & - \\
\hline & \multicolumn{2}{|c|}{14} & 0.60 & 14.89 & - \\
\hline & \multicolumn{2}{|c|}{16} & 4.03 & - & - \\
\hline & \multicolumn{2}{|c|}{28} & 100 & 100 & - \\
\hline \multicolumn{3}{|c|}{$\begin{array}{l}\text { Sensitivities } \\
\text { (div./ } / \mu \mathrm{L})\end{array}$} & 30.6 & 28.3 & 9.86 \\
\hline \multicolumn{3}{|c|}{$\begin{array}{l}\text { Relative } \\
\text { sensitivities }\end{array}$} & 1 & 0.93 & 0.32 \\
\hline \multicolumn{2}{|c|}{$\begin{array}{c}\text { Detectable } \\
\text { limits }\end{array}$} & $\begin{array}{l}\mu \mathrm{L} \\
\mu \mathrm{g}\end{array}$ & $\begin{array}{l}0.1 \\
0.07^{*}\end{array}$ & $\begin{array}{l}0.1 \\
0.1\end{array}$ & $\begin{array}{l}0.05 \\
0.005\end{array}$ \\
\hline
\end{tabular}

* As oxygen

ponent peak of hydrogen. Carbon monoxide and nitrogen have fragment ions at $M / e=12,14,16,28$ and $M / e=14,28$, respectively, as shown in Table 3 , so that the amount of each component cannot be calculated directly from the peak height. The simultaneous equations using two peak heights should be used in the calculation. The back ground spectrum by water vapor is seen at $M / e=16$, and the peak height varies so largely from time to time that it cannot be used in the analysis. The methods using the peak height of $M / e$ $=12$ and 28 , and $M / e=14$ and 28 have been tried on the synthetic mixtures of carbon monoxide and nitrogen. The method using the peak height of $M / e=12$ and 28 is better than that of $M / e=14$ and 28 over all the ratio of mixture as shown in Table 4 .

Table 4 Analysis of synthetic mixtures of carbon monoxide and nitrogen

\begin{tabular}{c|c|c|c|c}
\hline $\begin{array}{c}\text { Gas } \\
\text { mixtures }\end{array}$ & \multicolumn{2}{|c|}{ Found } & \multicolumn{2}{c}{ Differences } \\
\hline $\begin{array}{c}\text { Added } \\
\text { carbon } \\
\text { monoxide } \\
(\%)\end{array}$ & \multicolumn{2}{|c|}{ Carbon monoxide (\%) } & \multicolumn{2}{c}{ (Found)-(Added) } \\
\cline { 2 - 5 } \cline { 2 - 4 } & Method I & Method II & Method I & Method II \\
79.21 & 78.50 & 77.13 & -0.71 & -2.08 \\
63.36 & 61.90 & 64.49 & -1.46 & +1.13 \\
50.57 & 49.06 & 52.63 & -1.51 & +2.06 \\
34.67 & 33.22 & 39.89 & -1.45 & +5.22 \\
21.11 & 19.89 & 28.29 & -1.22 & +7.18 \\
\hline
\end{tabular}

Method I : Used peaks of $M / e=12$ and 28

Method II :-Used peaks of $M / e=14$ and 28

The concentration of each component in the specimens is calculated by the following equations.

Oxygen $(\%)=V_{0} \times K \times 0.714 \times 100 /$ weight of specimen in grams 
Nitrogen $(\%)=V_{n} \times K \times 0.125 \times 100 /$ weight of specimen in grams

Hydrogen $(\%)=V_{h} \times K \times 0.009 \times 100 /$ weight of specimen in grams where $V_{0}, V_{n}$ and $V_{n}$ are the milliliters of carbon monoxide, nitrogen and hydrogen detected respectively. $K$ is $273 \mathrm{~B} / 760(273+t)$ ( $\mathrm{B}$ is the atmospheric pressure in $\mathrm{mmHg}$ and $t$ is the temperature of gases).

The mass spectra of the extracted gases and the blank gases are shown in Fig. 3 as an example.

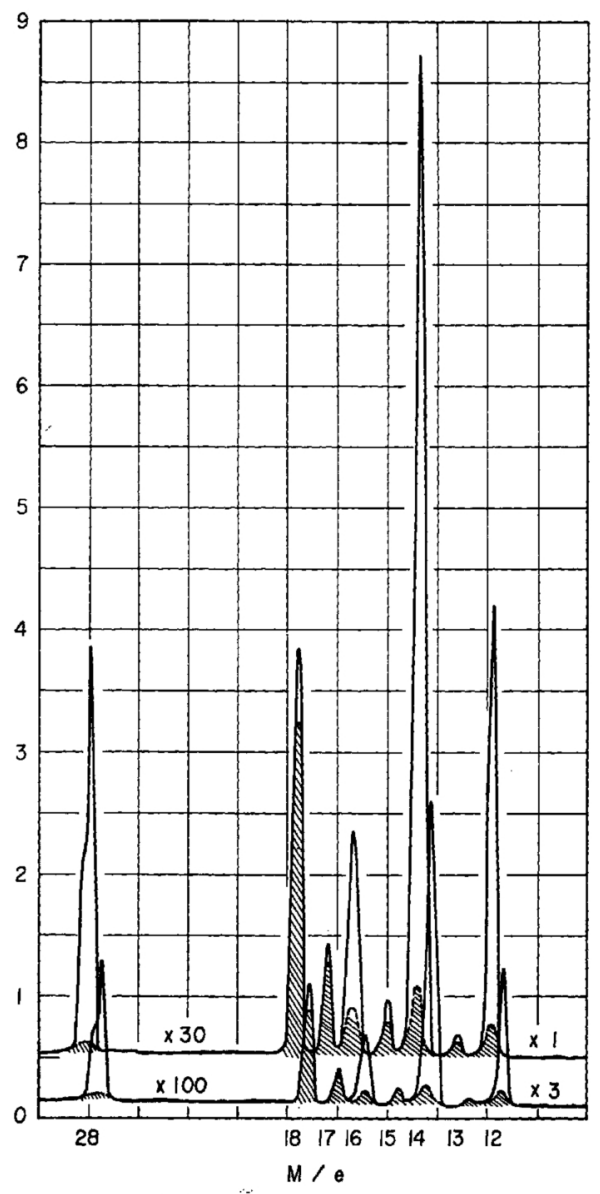

Fig.3 Mass spectra of extracted igs : Sample: Hard steel wire rods, $1 \mathrm{~g}$ Extraction : Temp., $1700^{\circ} \mathrm{C}$, Time, 5 min (Shaded for blank gas)

\section{Experimental}

\section{Time of extraction}

In order to observe the rate of extraction of gases from the specimen, peaks at $M / e=28$ and 12 were traced using hard steel wire rods at $1700^{\circ} \mathrm{C}$ as shown in Fig. 4. In this graph, the curves of $M / e=12$ show the extraction of carbon monoxide and the curves of $M / e=28$ show the extraction of carbon monoxide and nitrogen in all. From this it is clear that about $80 \%$ of the gases in a specimen is evolved in 1 minute, and all the gases in 2 minutes. The rate of extraction and the time required for the extraction may vary with the kind and the size of specimens, but the results of our experiment on the other carbon steel, low and high alloy steel were so similar to Fig. 4, and the extraction curves for the specimens weighing $1.7 \mathrm{~g}$ were not so different from Fig. 4 that the time for the extraction was decided as 5 minutes in this experiment.

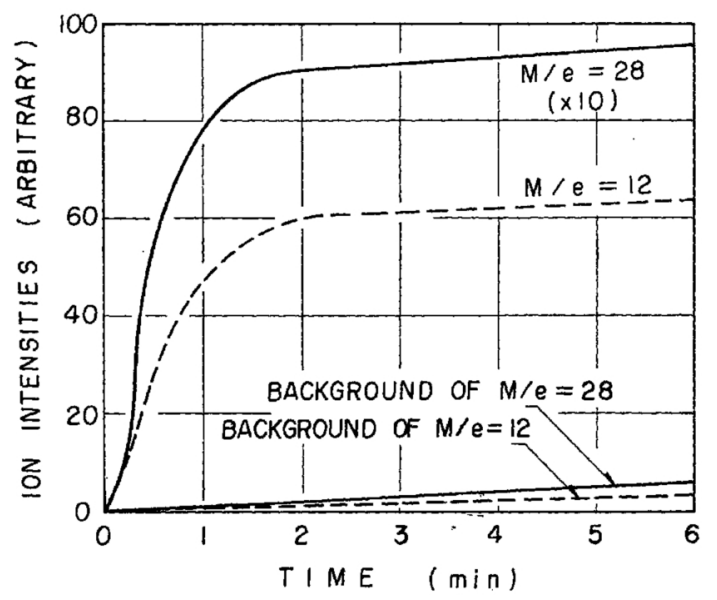

Fig.4 Extration curve of gases in steel Furnace temp. : $1700^{\circ} \mathrm{C}$

Sample : Hard steel wire rods $0.7 \mathrm{~g}$

\section{Sample size}

Since the proposed method is highly sensitive, even a very small specimen can be analyzed. But in a small specimen, the precision and the accuracy of the determination may be worse than a large specimen, so the effects of the size of specimens on the analytical value were investigated using homogeneous hard steel wire rods. Figures of Table 5 on the $0.7 \mathrm{~g}$ and $0.3 \mathrm{~g}$ specimens were analyzed statistically.

For oxygen

$F_{0}=1.65<F_{13}{ }^{16}(0.01)=3.78$ (from $F$-distribution),

$t_{0}=1.90<t(29,0.01)=2.756$ (from $t$-distribution), for nitrogen

$F_{0}=3.14<F_{13}{ }^{16}(0.01)=3.78$,

$t_{0}=2.47<t(29,0.01)=2.756$.

For both components, there is no evidence of the difference of the precision and bias between $0.7 \mathrm{~g}$ and

Table 5 Effects of sample size on analytical values

\begin{tabular}{|c|c|c|c|c|}
\hline $\begin{array}{l}\text { Sample } \\
\text { size }\end{array}$ & Element & $\begin{array}{l}\text { Contents } \\
\text { (ppm wt) }\end{array}$ & $\begin{array}{r}\text { Mean } \\
(\mathrm{ppm} \\
\mathrm{wt})\end{array}$ & $\begin{array}{l}\text { Standard } \\
\text { deviation }\end{array}$ \\
\hline \multirow{3}{*}{$0.7 \mathrm{~g}$} & Oxygen & $\begin{array}{l}37,39,38,39,36,38,33 \\
33,40,38,35,35,33,38\end{array}$ & 36.6 & 2.3 \\
\hline & Nitrogen & $\begin{array}{l}29,23,18,25,18,22,22 \\
18,21,33,30,19,39,13\end{array}$ & 23.2 & 6.6 \\
\hline & Hydrogen & $\begin{array}{l}1.8,1.1,0.8,1.3,3.0,2.8, \\
1.1,0.8,2.5,1.1,2.3,1.2, \\
0.8,0.8\end{array}$ & 1.5 & 0.8 \\
\hline \multirow{3}{*}{$0.3 \mathrm{~g}$} & Oxygen & $\begin{array}{l}34,38,38,36,41,40,43 \\
39,27,45,39,36,39,40, \\
44,38,40\end{array}$ & 38.6 & 4.0 \\
\hline & Nitrogen & $\begin{array}{l}15,19,15,23,21,16,17, \\
16,25,22,15,20,16,21 \text {, } \\
20,15,16\end{array}$ & 18.4 & 3.1 \\
\hline & Hydrogen & $\begin{array}{l}0.6,0.2,0.6,0.8,0.8,1.0 \\
1.0,0.8,1.5,1.6,0.7,0.5 \\
0.6,0.3,1.7,0.4,0.5\end{array}$ & 0.8 & 0.4 \\
\hline
\end{tabular}

Samples : Hard steel wire rods 
$0.3 \mathrm{~g}$ at $1 \%$ level. But the values of hydrogen is affected by the size, so hydrogen should be determined with precaution.

\section{Application}

The results of the determination of gases in iron and steel by the proposed method are shown in Tables 6

Table 6 Determinations of oxygen in steel

\begin{tabular}{|c|c|c|c|c|}
\hline Samples & Contents & Mean & $\begin{array}{l}\text { Standard } \\
\text { deviation }\end{array}$ & $\begin{array}{l}\text { Relative } \\
\text { std. dev. }\end{array}$ \\
\hline $\begin{array}{c}\mathrm{A} \\
(25)\end{array}$ & $\begin{array}{l}21.5,22.2,20.9,22.0,18.9 \\
19.8,17.2,20.7,22.6,19.0 \text {, } \\
17.9\end{array}$ & 20.2 & 1.8 & $8.9 \%$ \\
\hline$\underset{(280)}{\text { B }}$ & $\begin{array}{l}260,288,294,307,310,281, \\
297,321,298,286,304\end{array}$ & 295 & 16.5 & $5.6 \%$ \\
\hline
\end{tabular}

A : Hard steel wire rods

B : Wire rod for core wire of arc coated electrodes

() : Result by cooperative experiments

\section{Conclusions}

An apparatus for the analysis of micro-amounts of gases in iron and steel by vacuum fusion-mass spectrometry was developed, and its characteristics, such as analytical procedure, sensitivity, suitability, applicability and the time of the extraction, were investigated.

The following results were obtained.

(1) The proposed method shows high sensitivity and the detectable limits are as follows.

Oxygen : $0.07 \mu \mathrm{g}$, nitrogen : $0.1 \mu \mathrm{g}$,

hydrogen : $0.005 \mu \mathrm{g}$

(2) The gases in specimens are quantitatively extracted in 2 minutes.

(3) The analytical procedure is very simple, and the time required for analysis is 30 minutes excluding the sample preparation and the calculation.

(4) Even for small samples $(0.3 \mathrm{~g})$, there is no evidence of the difference in the precision and bias from large samples.

Table 7 Determinations of gases in iron and steel standard samples (ppm wt)

\begin{tabular}{|c|c|c|c|c|c|c|c|}
\hline \multirow{2}{*}{\multicolumn{2}{|c|}{ Samples }} & \multicolumn{2}{|c|}{ Oxygen } & \multicolumn{2}{|c|}{ Nitrogen } & \multicolumn{2}{|c|}{ Hydrogen } \\
\hline & & $\begin{array}{c}\text { This method } \\
172\end{array}$ & Certificated & $\frac{\text { This method }}{33}$ & Certificated & $\begin{array}{c}\text { This method } \\
0.8\end{array}$ & $\begin{array}{c}\text { Certificated } \\
-\end{array}$ \\
\hline $\begin{array}{c}\text { NBS } \\
\text { NBS } \\
\text { NBS } \\
\text { BAM } \\
\text { BAM } \\
\text { BAM } \\
\text { H. S. }\end{array}$ & $\begin{array}{c}1041 \\
1045 \\
1047 \\
01 \\
02 \mathrm{a} \\
04 \\
\mathrm{R}\end{array}$ & $\begin{array}{c}172 \\
86 \\
170 \\
154 \\
199 \\
27.6 \\
28\end{array}$ & $\begin{array}{c}170 \\
70 \\
170 \\
157 \\
175 \\
33.4 \\
26 * 1\end{array}$ & $\begin{array}{l}33 \\
33 \\
25 \\
- \\
- \\
-\end{array}$ & $\begin{array}{l}40 \\
40 \\
40 \\
- \\
- \\
\overline{87} * 2\end{array}$ & $\begin{array}{l}0.8 \\
0.4 \\
0.8 \\
- \\
- \\
\overline{0.5}\end{array}$ & $\begin{array}{l}\bar{z} \\
\overline{-} \\
\overline{-} \\
\overline{0.5^{* 3}}\end{array}$ \\
\hline
\end{tabular}

H. S. W. R : Hard steel wire rods. This sample have used as checking sample by authors

$*_{1}$ Value by the vacuum fusion-micro-orsat

*2 Value by Kjeldahl

*3 Value by the high temperature extraction

and 7. The results are satisfactory, for oxygen but not for nitrogen. Therefore, further studies are necessary for the analysis of nitrogen. Carbon dioxide, methane and ethylene were detected from the extracted gases, but their amounts were so small that the correction by them was not necessary.

\section{Acknowledgment}

The authors wish to thank Prof. Shun Araki of Tokyo Metropolitan Univ. for his interest and valued advice in this work. 